\title{
Metabolome response to temperature- induced virulence gene expression in two genotypes of pathogenic Vibrio parahaemolyticus
}

\author{
Bo Feng ${ }^{1}$, Zhuoran Guo ${ }^{1}$, Weijia Zhang ${ }^{1,2,3}$, Yingjie Pan ${ }^{1,2,3}$ and Yong Zhao ${ }^{1,2,3^{*}}$
}

\begin{abstract}
Background: Vibrio parahaemolyticus is a main causative agent of serious human seafood-borne gastroenteritis disease. Many researchers have investigated its pathogenesis by observing the alteration of its virulence factors in different conditions. It was previously known that culture conditions will influence the gene expression and the metabolic profile of $V$. parahaemolyticus, but little attention has been paid on the relationship between them. In this study, for the first time, the metabolomics response in relation to the expression of two major virulence genes, tdh and trh, induced at three temperatures $\left(4,25\right.$ and $\left.37^{\circ} \mathrm{C}\right)$ was examined in two genotypes of pathogenic Vibrio parahaemolyticus (ATCC33846 (tdh+/trh-/t/h+) and ATCC17802 (tdh-/trh+/t/h+)).
\end{abstract}

Results: Reverse transcription real-time PCR (RT-qPCR) analysis illustrated that the expression levels of $t d h$ and trh induced at $25^{\circ} \mathrm{C}$ in $\mathrm{V}$. parahaemolyticus were significantly higher than those induced at 4 and $37^{\circ} \mathrm{C}$. Principal components analysis (PCA) based on the UPLC \& Q-TOF MS data presented clearly distinct groups among the samples treated by different temperatures. Metabolic profiling demonstrated that 179 of 1,033 kinds of identified metabolites in ATCC33846 changed significantly $(p<0.01)$ upon culturing at different temperatures, meanwhile 101 of 930 kinds of metabolites changed $(p<0.01)$ in ATCC17802. Pearson's correlation analysis highlighted the correlation between metabolites and virulence gene expression levels. At the threshold of $|r|=1, p<0.01,12$ kinds of metabolites showed extremely significant correlations with tdh expression, and 4 kinds of metabolites significantly correlated with trh expression. It is interesting that 3D, 7D, 11D-Phytanic acid showed the same trend with pyrophosphate, whose derivative could activate the degradation of phytanic acid. Several metabolites could be sorted into the same class by the method of chemical taxonomy, by assuming that they are involved in the same metabolic pathways.

Conclusions: This research can help to find biomarkers to monitor virulence gene expression, and can further help laboratory and clinical research of $V$. parahaemolyticus from the perspective of metabolomics.

Keywords: Vibrio parahaemolyticus, Relative virulence gene expression, Metabolic profiling, Pearson's correlation analysis

\footnotetext{
* Correspondence: yzhao@shou.edu.cn

${ }^{1}$ College of Food Science and Technology, Shanghai Ocean University, No.

999 Hu Cheng Huan Road, Shanghai, China

${ }^{2}$ Shanghai Engineering Research Center of Aquatic-Product Processing \&

Preservation, Shanghai, China

Full list of author information is available at the end of the article
} 


\section{Background}

Vibrio parahaemolyticus is a gram-negative and halophilic bacterium, known as a leading cause of seafoodborne poisoning all over the world [1-3]. Numerous outbreaks of food-borne disease were associated with V. parahaemolyticus infection [4-6]. Most people are infected by eating raw or undercooked shellfish, particularly oysters. $V$. parahaemolyticus can also cause systemic infection through wound infection [7].

The pathogenesis of $V$. parahaemolyticus is complex. As we known, $V$. parahaemolyticus strains contain a number of different virulence factors including adhesins, thermostable direct hemolysin (TDH), TDH-related hemoysin $(\mathrm{TRH})$, two type III secretion systems, T3SS1 and T3SS2 $[8,9]$. Two co-existed type VI secretion systems, T6SS1 and T6SS2, would be new virulence factors of $V$. parahaemolyticus $[10,11]$. Previous studies have found that pathogenic $V$. parahaemolyticus often carries thermostable direct hemolysin ( $t d h)$ and/or thermostable-related hemolysin (trh) genes [12-14]. TDH and TRH were first identified as $V$. parahaemolyticus virulence factors in the 1980s, and then considered as the main toxins which induce cytotoxicity and enterotoxicity [15-17]. In recently years, though research about regulatory mechanism of virulence has been discovered [18], there were few discussions about the correlation between growth condition and virulence gene expression of $V$. parahaemolyticus. Studies of virulence factors have made remarkable progress, while the synergy effect and pathogenicity of them are still under investigation [9].

The rapid development of metabolomics introduced a powerful way to study the pathogenesis of diseases by analyzing the metabolites of patients and monitoring the alteration of biomarkers in the course of diseases [19]. Metabolomics could be valued as a new vision for characterization of a pathogen during its growth and infection process. It has been confirmed that there is correlation between genes and metabolites in E. coli [20], but little attention has been paid to the analysis of the metabolome for better understanding the pathogenesis of $V$. parahaemolyticus. So it is meaningful to research the virulence gene expression, the metabolic situation of $V$. parahaemolyticus, and most significantly, the correlationship between them.

Previous research of our group has detected $t d h$ and th expression in $V$. parahaemolyticus by reverse transcription real-time PCR (RT-qPCR) [21] and distinguished different pathogenic $V$. parahaemolyticus strains based on metabolic profiling [22]. This research focused on investigating the correlation between the virulence gene expression of $V$. parahaemolyticus and its metabolites induced at three temperatures, for better understanding its pathogenesis and monitoring typical virulent $V$. parahaemolyticus strains. Three temperatures, 4,25 and $37{ }^{\circ} \mathrm{C}$, were chosen as the incubation temperatures for simulating the storage temperature of fresh aquatic products, environmental temperature and human body temperature. The $t d h$ and trh gene were chosen as the virulence genes to be studied in this research. Relative virulence gene expression of two standard pathogenic strains of $V$. parahaemolyticus, ATCC33846 $(t d h+/ t r h-/ t h+)$ and ATCC17802 $(t d h-/ t r h+/ t h+)$, were performed by RT-qPCR. Metabolic profiling of $V$. parahaemolyticus was determined by Ultra Performance Liquid Chromatography \& Quadrupole-Time-ofFlight Mass Spectrometry (UPLC \& Q-TOF MS). Furthermore, the relationship between metabolome and virulence gene expression was explored by Pearson's correlation analysis.

\section{Results}

\section{Virulence gene expression of $V$. parahaemolyticus}

The virulence gene expression of two genotypes of $V$. parahaemolyticus were investigated by RT-qPCR under different culture conditions $\left(4,25\right.$ and $\left.37^{\circ} \mathrm{C}\right)$. Both $p v u A$ and $p v s A$ were used as the reference genes due to the bias which may be caused by the fluctuation in expression level of a single reference gene [23]. The expression levels of $t d h$ induced at $25{ }^{\circ} \mathrm{C}$ in $V$. parahaemolyticus ATCC33846 (tdh+/trh-/th+) were approximately two-fold higher than those induced at 4 and $37^{\circ} \mathrm{C}(p<0.05)$ (Fig. 1a). The expression of the trh gene presented the same trend in $V$. parahaemolyticus ATCC17802 (tdh-/trh+/tlh+) (Fig. 1b).

\section{Metabolic profiling of $V$. parahaemolyticus}

To generate an overview of the data set, the positive and negative ions were detected and processed by MassLynx 4.1, and then the data were fed to SIMCA-P 11.5 for principal components analysis (PCA). PCA was performed to validate the differences between the metabolites in $V$. parahaemolyticus affected by different temperatures. Figure 2 showed the scatter plot using the score of first principal component (PC1) and the second principal component (PC2) for each sample. In general, the $V$. parahaemolyticus samples were clustered in three distinct groups according to temperatures $\left(4,25\right.$ and $\left.37{ }^{\circ} \mathrm{C}\right)$. The close clustering of the $V$. parahaemolyticus samples indicated their high similarity in terms of their metabolites compositions and abundances.

Typical UPLC \& Q-TOF MS chromatograms of $V$. parahaemolyticus were analyzed. According to UPLCMS data, over 5000 peaks were determined in the two strains of bacteria grown at 4, 25 and $37{ }^{\circ} \mathrm{C}$. Every peak was identified as a certain metabolite by searching its value of $\mathrm{m} / \mathrm{z}$ in HMDB. The value of relative 


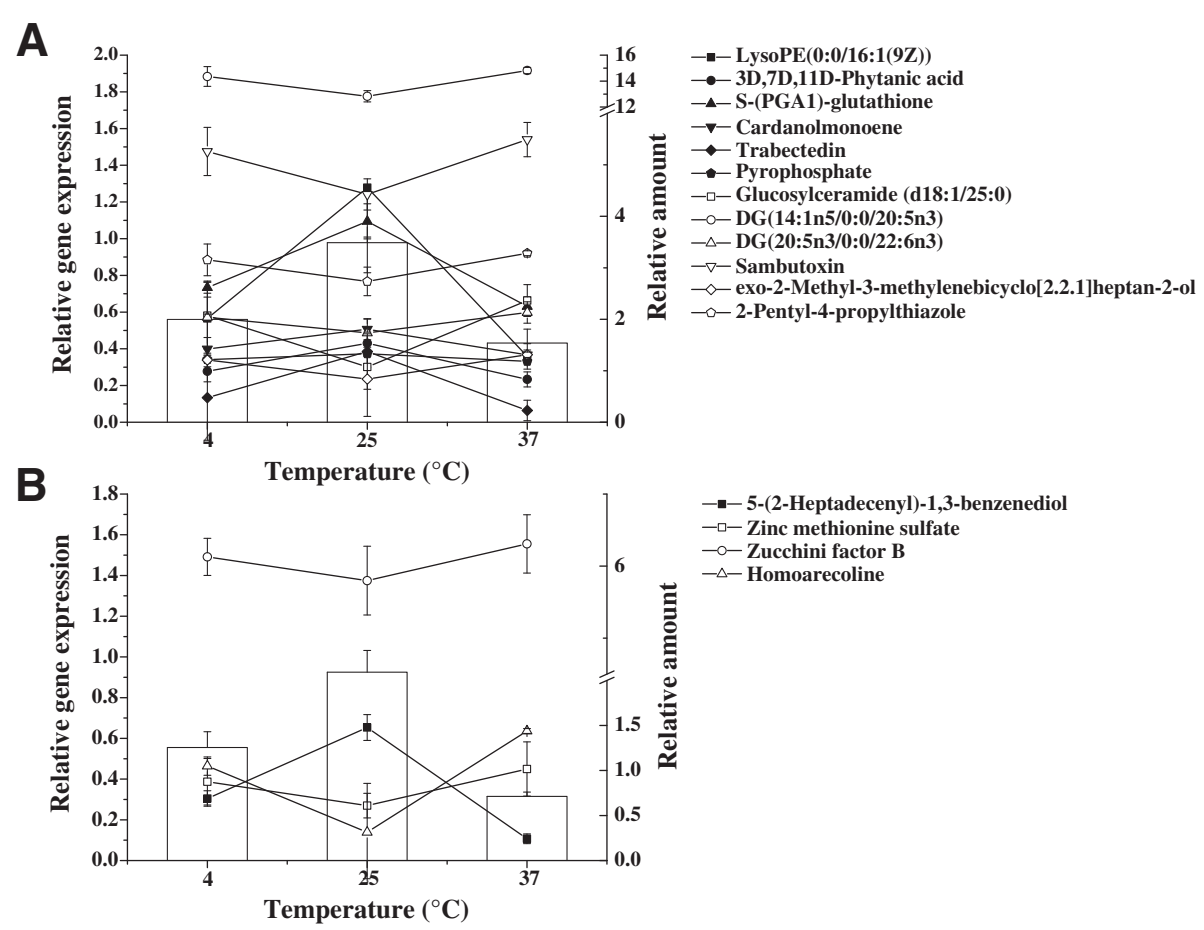

Fig. 1 Relative quantifications of gene expressions and metabolites in $V$. parahaemolyticus. a tdh gene expression (column) and 12 kinds of metabolites (line) which had extremely high correlation with tdh gene expression $(|r|=1, p<0.01)$ in ATCC33846. Relative amount of six kinds of metabolites illustrated positive correlation with relative gene expression under different temperatures; the other six kinds of metabolites showed negative correlation. $\mathbf{b}$ trh gene expression (column) and four kinds of metabolites (line) which had extremely high correlation with trh gene expression (| $\mathrm{r} \mid=1$, $p<0.01)$ in ATCC17802. One metabolite illustrated positive correlation with gene expression; the other three metabolites showed negative correlation

concentration of metabolite was used for statistical analysis (Additional file 1: Table S1 and Additional file 2: Table S2). The number of identified peaks, total numbers of identified metabolites, and numbers of metabolites changed significantly and numbers of metabolites highly correlated with $t d h / t r h$ expression level were shown in Table 1. There are 179 and 101 kinds of metabolites changed with incubation temperature significantly in ATCC33846 and ATCC17802, respectively. Heatmaps were employed to visualize the variations of metabolites concentration, which containing hierarchical clustering on the left (Figs. 3 and 4). Metabolites

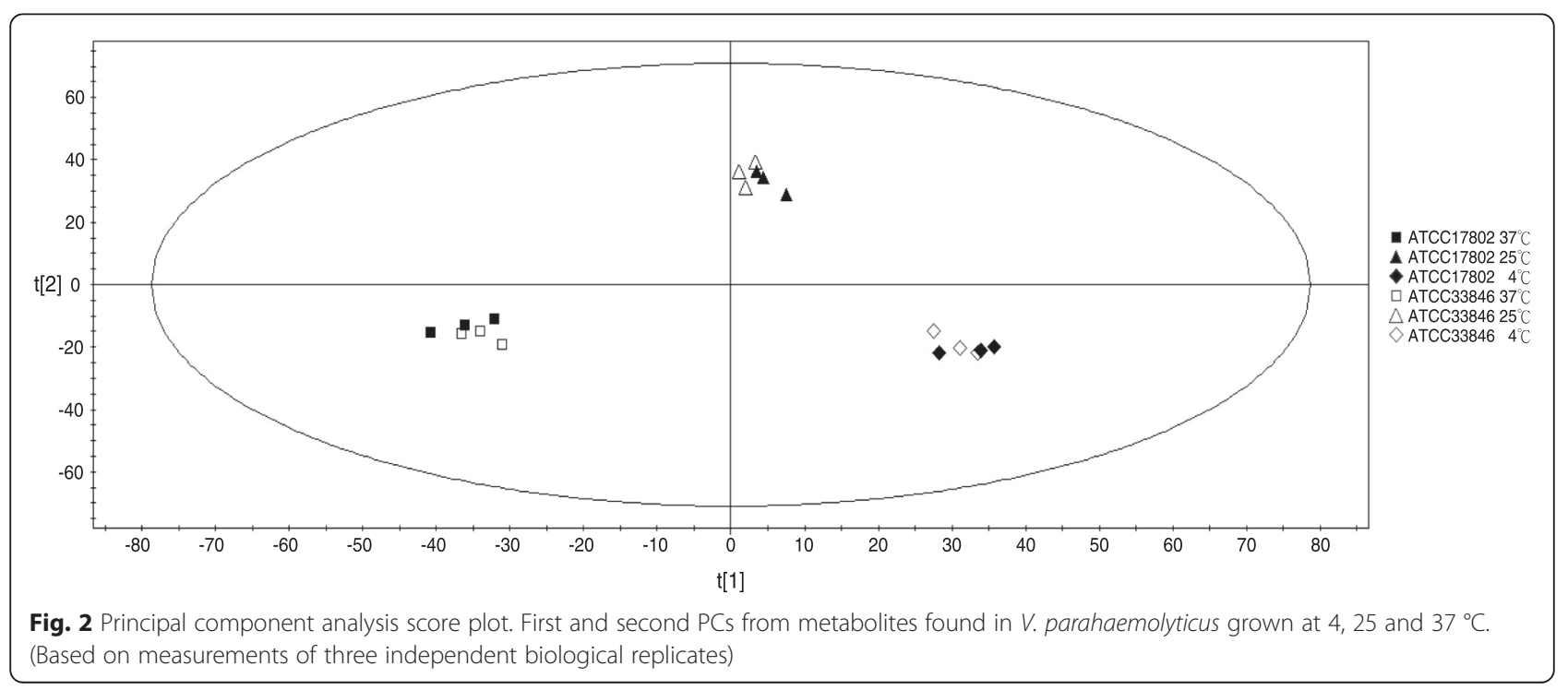


Table 1 Metabolic profiling of $V$. parahaemolyticus grown at different temperatures

\begin{tabular}{|c|c|c|c|c|c|c|}
\hline \multirow[t]{2}{*}{ Strains } & \multicolumn{3}{|c|}{ Numbers of peaks identified at different temperatures } & \multirow{2}{*}{$\begin{array}{l}\text { Total numbers of } \\
\text { metabolites identified }\end{array}$} & \multirow{2}{*}{$\begin{array}{l}\text { Numbers of metabolites } \\
\text { changed significantly at } \\
\text { different temperatures } \\
(p<0.01)\end{array}$} & \multirow{2}{*}{$\begin{array}{l}\text { Numbers of metabolites } \\
\text { highly correlated with } \\
t d h / \text { trh expression level } \\
(|r|>0.8)\end{array}$} \\
\hline & $4{ }^{\circ} \mathrm{C}$ & $25^{\circ} \mathrm{C}$ & $37^{\circ} \mathrm{C}$ & & & \\
\hline ATCC33846 & 882 & 1,011 & 916 & 1,033 & 179 & 388 \\
\hline ATCC17802 & 847 & 887 & 868 & 930 & 101 & 345 \\
\hline
\end{tabular}

which were arranged nearby have similar variational rules of concentrations in different temperatures. The significantly changed metabolites could be classified into different categories by chemical taxonomy, such as alkaloids and derivatives, benzenoids, lipids and lipidlike molecules, nucleosides, nucleotides, and analogues, organic acids and derivatives, organoheterocyclic compounds, phenylpropanoids and polyketides (Additional file 3: Table S3 and Additional file 4: Table S4).

\section{Correlation between expression of $t d h / t r h$ and metabolome}

In previous studies, Pearson's correlation analysis was applied in examining the correlation between mRNA and protein abundance $[24,25]$. In this study, $t d h$ and trh gene expression were used for discussing the correlation with metabolites of ATCC33846 and ATCC17802, respectively. There were 388 (37.6 \%) and 345 (37.1 \%) kinds of metabolites that showed high correlationship $(|\mathrm{r}|>0.8)$ with the gene expression of $t d h$ and trh in ATCC33846 and ATCC17802, respectively (Table 1).

Following, the threshold of $|\mathrm{r}|=1, p<0.01$ was chosen for further insight into the relationship between the virulence gene expression and metabolome. There were 12 and four kinds of metabolites that showed extremely significant correlation with $t d h$ and $t r h$ gene expression level in ATCC33846 and ATCC17802, respectively (Table 2).

\section{Discussion}

$V$. parahaemolyticus, a major seafood-derived pathogen which can cause gastrointestinal illness in humans, has attracted more and more interest especially in its virulence in recent years $[8,9]$. Two virulence genes expression and metabolites profile were investigated at different incubation temperature. The relationship between them was explored for the first time.

In this study, both $t d h$ and trh gene expression showed a similar trend, that the expression level reached highest at $25{ }^{\circ} \mathrm{C}$. These results suggested that though $37^{\circ} \mathrm{C}$ was regularly used as the culturing temperature in $V$. parahaemolyticus for simulating actual environmental condition in the human gut, $25{ }^{\circ} \mathrm{C}$ was more conducive for virulence gene expression in culture medium.

Of thousands of metabolites, 200-300 kinds of them mainly changed, which including low-molecular-weight organic acids, amino acids, alcohols, ketones, esters, sugars and others. These same categories of metabolites were also detected in other microorganism, such as yeast [26] and Listeria monocytogenes [27]. Ewald et al. reported that the concentration of intracellular metabolites was determined by the molecular integration of genomic and environmental factors [28]. Meanwhile, the metabolic study on $E$. coli suggested that the concentration of some metabolites changed along with a certain gene mutation in continuous cultures [20]. Thus, the concentration of various metabolites in microorganisms may result from the change of culturing condition and gene expression.

So we hypothesized that there is a correspondence between metabolome and virulence gene expression; and both of them are impacted by culturing temperature.

In this study, based on statistical analysis, 12 and four metabolites showed extremely significant correlation with $t d h$ and $t r h$ gene expression, respectively. The alteration rules of metabolites and virulence gene expression are correlated together by the regulation of culturing temperature. Not much research is available about discussing metabolites and their function in the life cycle of microorganism. Nevertheless we found a few possible connections between several of them or characteristics in metabolic process. 3D, 7D, 11D-Phytanic acid is a branched chain fatty acid, and could be a kind of Fatty-acid metabolic intermediate. It undergoes $\alpha$ oxidation in the cytosol, where it is converted into pristanic acid by the removal of one carbon [29]. In the third process of $\alpha$-oxidation, 2-hydroxyphytanoyl-CoA is cleaved by 2-hydroxyphytanoyl-CoA lyase in a TPPdependent reaction to form pristanal and formyl-CoA. TPP consists of a pyrimidine ring which is connected to a thiazole ring, which is in turn connected to a pyrophosphate functional group. Coincidentally, pyrophosphate changes with 3D, 7D, 11D-Phytanic acid at the same trend in our data suggesting they might be involved in the same metabolic pathway. LysoPE(0:0/ $16: 1(9 \mathrm{Z})$ ) is a lysophosphatidylethanolamine (LPE) or a lysophospholipid (LPL). It could transfer to different derivatives by simple enzymatic action. Some LPLs serve important signaling functions [30] in cells and might be a signal molecule for answering the alteration of environmental factors. Homoarecoline, isolated from betel nuts, belongs to the class of organic compounds known as alkaloids and derivatives of arecoline. Arecoline is known to be a partial agonist of muscarinic 


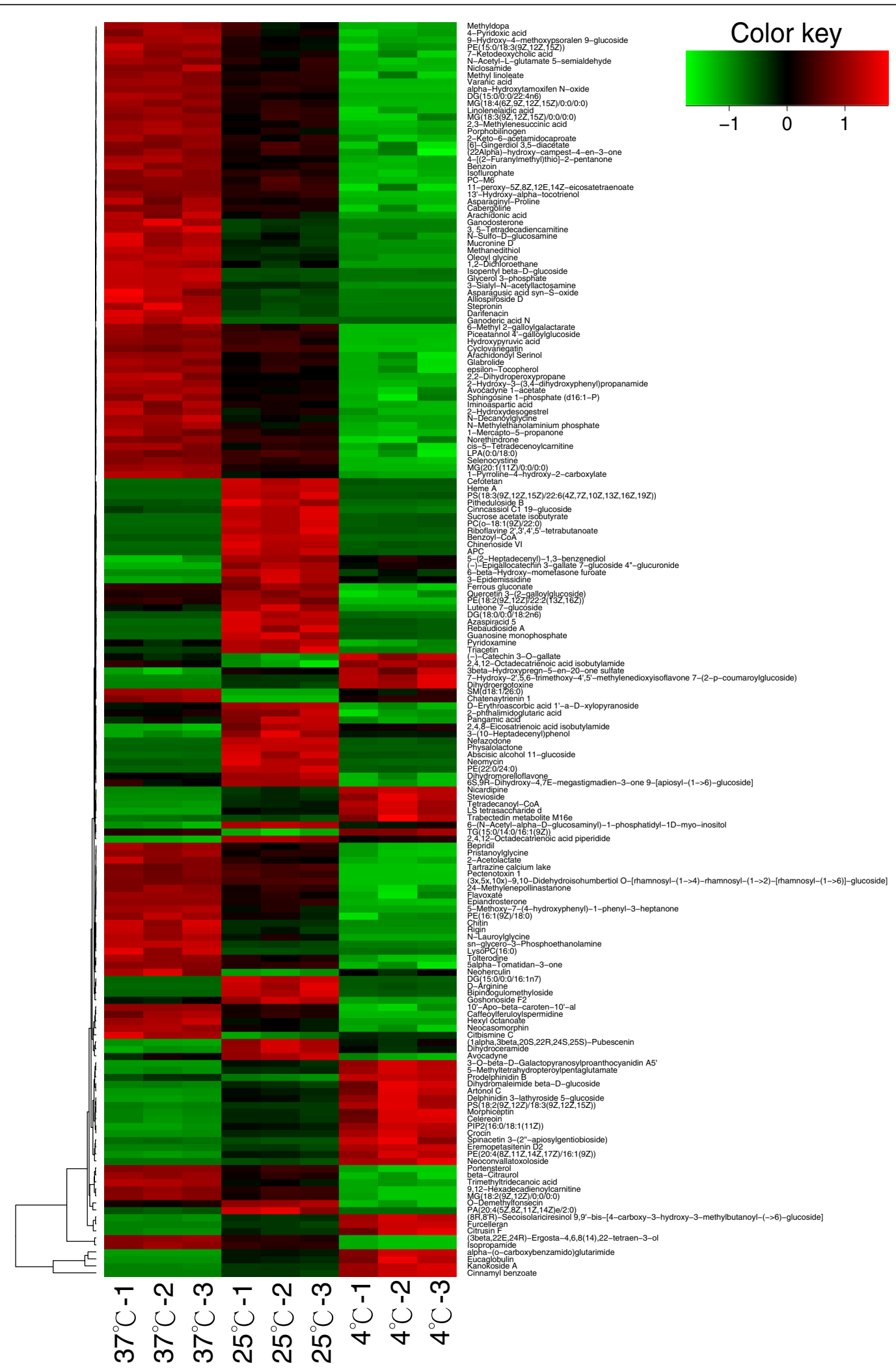

Fig. 3 Heatmap of the metabolite whose concentration changed significantly $(p<0.01)$, grouped by different culturing temperatures in ATCC33846. Colors represent an increase and decrease of metabolite (see color key). The dendrogram for metabolite clustering is shown on the left 


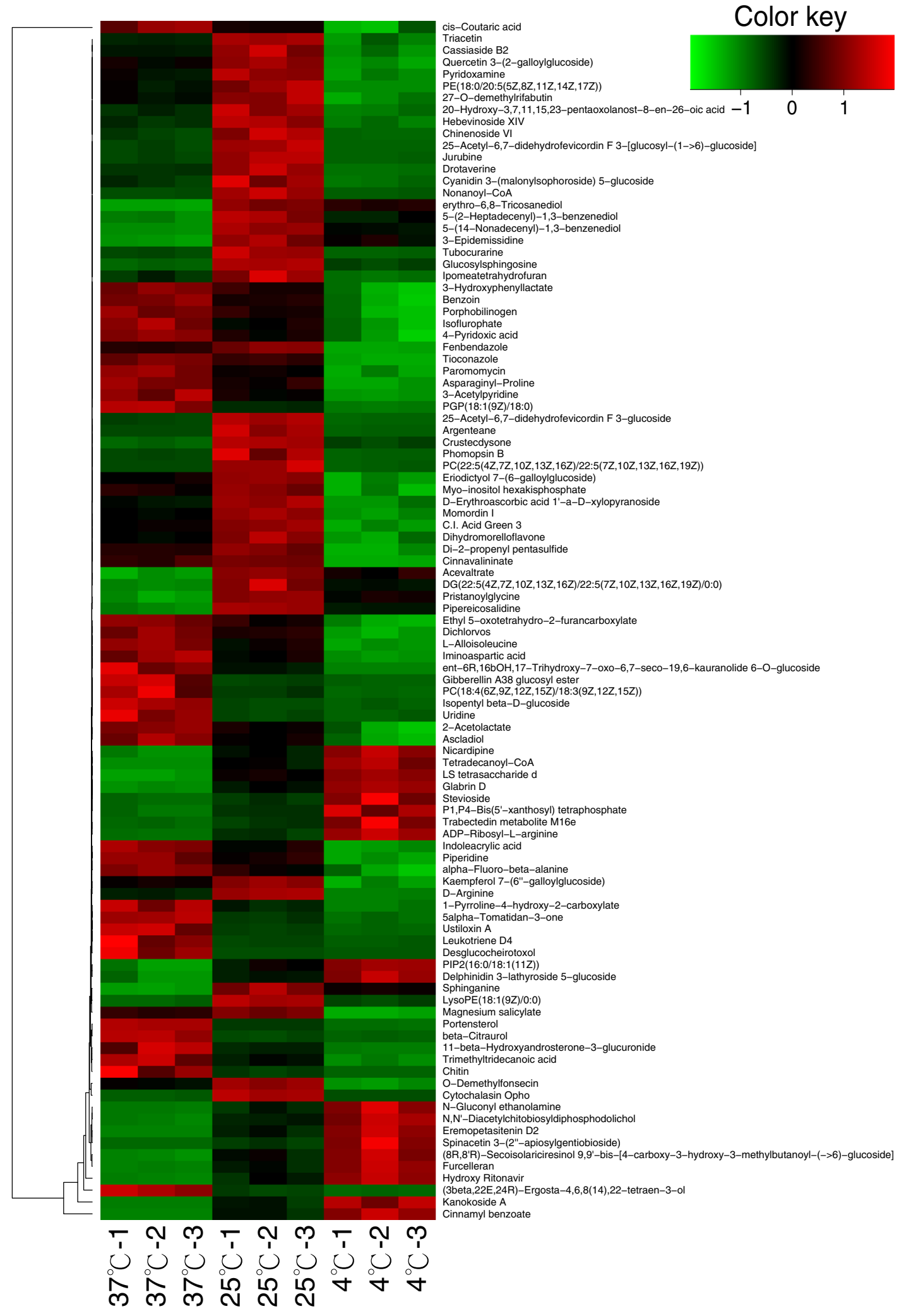

Fig. 4 Heatmap of the metabolite whose concentration changed significantly $(p<0.01)$, grouped by different culturing temperatures in ATCC17802. Colors represent an increase and decrease of metabolite (see color key). The dendrogram for metabolite clustering is shown on the left 
Table 2 The metabolites highly correlated with the expression level of $t d h$ and trh genes

\begin{tabular}{|c|c|c|c|}
\hline Gene & Compounds & Correlation coefficient & $p$-value \\
\hline$t d h$ & LysoPE(0:0/16:1(9Z)) & $1.000^{\mathrm{a}}$ & 0.001 \\
\hline$t d h$ & 3D,7D,11D-Phytanic acid & $1.000^{\mathrm{a}}$ & 0.002 \\
\hline$t d h$ & S-(PGA1)-glutathione & $1.000^{\mathrm{a}}$ & 0.003 \\
\hline$t d h$ & Cardanolmonoene & $1.000^{\mathrm{a}}$ & 0.004 \\
\hline$t d h$ & Trabectedin & $1.000^{\mathrm{a}}$ & 0.006 \\
\hline$t d h$ & Pyrophosphate & $1.000^{\mathrm{a}}$ & 0.008 \\
\hline$t d h$ & Glucosylceramide (d18:1/25:0) & $-1.000^{\mathrm{a}}$ & 0.001 \\
\hline$t d h$ & DG(14:1n5/0:0/20:5n3) & $-1.000^{\mathrm{a}}$ & 0.004 \\
\hline$t d h$ & DG(20:5n3/0:0/22:6n3) & $-1.000^{\mathrm{a}}$ & 0.005 \\
\hline$t d h$ & Sambutoxin & $-1.000^{\mathrm{a}}$ & 0.006 \\
\hline$t d h$ & exo-2-Methyl-3-methylenebicyclo[2.2.1]heptan-2-ol & $-1.000^{\mathrm{a}}$ & 0.007 \\
\hline$t d h$ & 2-Pentyl-4-propylthiazole & $-1.000^{\mathrm{a}}$ & 0.008 \\
\hline $\operatorname{trh}$ & 5-(2-Heptadecenyl)-1,3-benzenediol & $1.000^{\mathrm{a}}$ & 0.008 \\
\hline trh & Zinc methionine sulfate & $-1.000^{\mathrm{a}}$ & 0.002 \\
\hline $\operatorname{trh}$ & Zucchini factor B & $-1.000^{\mathrm{a}}$ & 0.002 \\
\hline trh & Homoarecoline & $-1.000^{\mathrm{a}}$ & 0.003 \\
\hline
\end{tabular}

${ }^{\text {a }}$ Presented correlation is significant at 0.01 level

acetylcholine M1, M2, M3 receptors and M4, [31-33] which is believed to be the primary cause of its parasympathetic effects. Arecoline has also been used medicinally as an antihelmintic [34]. In addition, DG(14:1n5/0:0/ 20:5n3), DG(20:5n3/0:0/22:6n3), exo-2-Methyl-3-methylenebicyclo[2.2.1]heptan-2-ol and Glucosylceramide (d18:1/ 25:0), are lipids or lipid-like molecules in $V$. parahaemolyticus ATCC33846; 5-(2-Heptadecenyl)-1,3-benzenediol and zucchini factor B are benzene and substituted derivatives in $V$. parahaemolyticus ATCC17802.

We believe that once increasing experimental evidences are explored in metabolic pathways, these metabolites which have been screened out could be developed as biomarkers or regulators for $V$. parahaemolyticus in future research. New biomarkers would be helpful in monitoring and rapid detection of virulence factors; some metabolites could be used as regulatory factors to control the growth of bacteria; and some potential metabolites might be developed as new drugs to treat diseases caused by $V$. parahaemolyticus.

\section{Conclusions}

This study proved that there is a correlation between the metabolome and virulence gene expression, under different culturing temperatures. This relationship provides a new perspective for better monitoring virulence performance and understanding pathogenesis of this bacteria. Moreover, some certain metabolites could be developed as biomarkers in future research of Vibrio parahaemolyticus.

\section{Methods}

\section{Strains and cultivation}

V. parahaemolyticus ATCC33846 and ATCC17802 were purchased from the American type culture collection and the stock cultures were maintained at $-80{ }^{\circ} \mathrm{C}$ in $25 \%$ glycerol solution. The frozen culture was activated in tryptic soy broth (TSB, Beijing Land Bridge Technology Company Ltd., Beijing, PRC) plus $3 \% \mathrm{NaCl}$ and incubated at $37{ }^{\circ} \mathrm{C}$ with two consecutive transfers after a $10 \mathrm{~h}$ incubation. One hundred $\mathrm{mL}$ TSB $(3 \% \mathrm{NaCl})$ in a $250 \mathrm{~mL}$ flask was inoculated with $200 \mu \mathrm{L}$ inoculum and incubated at $37{ }^{\circ} \mathrm{C}$ or $12 \mathrm{~h}$ with shaking at $180 \mathrm{r} / \mathrm{min}$, then shifted to 4,25 and $37{ }^{\circ} \mathrm{C}$ statically for $12 \mathrm{~h}$.

\section{Enumeration of bacteria}

Bacteria were counted according to the procedure described in a previous study [35] with some modifications. Briefly, the culture was serially diluted 10 -fold in $0.85 \%$ $\mathrm{NaCl}$ solution, and then $0.1 \mathrm{~mL}$ samples of each dilution were spread onto the thiosulfate citrate bile sucrose agar (TCBS, Beijing Land Bridge Technology Company Ltd., Beijing, PRC) plate. The bacteria counts were enumerated after incubation at $37^{\circ} \mathrm{C}$ for $24 \mathrm{~h}$.

\section{RNA extractions and CDNA synthesis}

Cells of the culture $(1 \mathrm{~mL})$ were harvested by centrifugation at $12,000 \mathrm{~g}$ for $5 \mathrm{~min}$, and resuspended in $1 \mathrm{~mL}$ Trizol reagent (Invitrogen, Carlsbad, USA) for $15 \mathrm{~min}$ and incubated at room temperature for $20 \mathrm{~min}$. Nucleic acids were recovered from the lysate by adding $200 \mu \mathrm{L}$ solution (phenol: chloroform: isoamyl alcohol $=25: 24: 1$ ) 
(Sangon, Shanghai, PRC), followed by centrifugation at $12,000 \mathrm{~g}$ for $15 \mathrm{~min}$ at $4{ }^{\circ} \mathrm{C}$. The aqueous layer was then transferred into a clean microcentrifuge tube. Nucleic acids were precipitated by adding equivalent isopropanol (Sangon, Shanghai, PRC) and pelleted by centrifugation at $12,000 \mathrm{~g}$ for $10 \mathrm{~min}$ at $4{ }^{\circ} \mathrm{C}$. The pellet was washed with $75 \%$ cold ethanol $\left(-20{ }^{\circ} \mathrm{C}\right)$ (Sangon, Shanghai, PRC) by centrifuged at $10,000 \mathrm{~g}$ for $5 \mathrm{~min}$ at $4{ }^{\circ} \mathrm{C}$, air dried, and resuspended in $30 \mu \mathrm{L}$ diethyl pyrocarbonate (DEPC) water (Sangon, Shanghai, PRC). RNA quality was checked on $1 \%$ agarose gel. Then the samples were stored at $-80^{\circ} \mathrm{C}$ for further analysis.

Reverse transcription (RT) was performed with $200 \mathrm{ng}$ total RNA using the PrimeScript RT reagent Kit with gDNA Eraser (Takara, Dalian, PRC) following the manufacturer's instructions.

\section{Quantitative real-time PCR analysis}

Relative gene expression was performed by real-time PCR using the ABI 7500 Fast quantitative PCR system (Applied Biosystems, Carlsbad, USA) and FastStart Universal SYBR Green Master (Rox) (Roche, Mannheim, Germany). Primers used in this study were described in Additional file 5: Table S5 and $p v u A$ and $p v s A$ were used as reference genes [36,37]. The primers of $t d h$ and $t r h$ gene were referenced the PCR detection method in the FDA bacteriological analytical manual [38]. Amplifications were performed in duplicate. The primers were diluted to $10 \mu \mathrm{M}$ before use. Each PCR was performed with a $20 \mu \mathrm{L}$ final volume containing $2 \mu \mathrm{L}$ cDNA, $1.5 \mu \mathrm{L}$ (each) primers, $5 \mu \mathrm{L} \mathrm{diH} \mathrm{H}_{2} \mathrm{O}, 10 \mu \mathrm{L} 1 \times$ SYBR Green PCR Master Mix (Roche). The following thermal cycling conditions were used: a denaturation program $\left(95{ }^{\circ} \mathrm{C}\right.$ for $10 \mathrm{~min}$ ), an amplification program repeated 40 times (95 ${ }^{\circ} \mathrm{C}$ for $15 \mathrm{~s}$ and $60{ }^{\circ} \mathrm{C}$ for $1 \mathrm{~min}$ ). Negative controls (deionized water) were included in each run. Melt curve analysis was performed on the PCR products at the end of each run to ensure that a single product was amplified. Relative quantification was measured using the $2^{-\Delta \Delta C t}$ method (the amount of target, normalized to an endogenous control and relative to a calibrator, where $\Delta \Delta \mathrm{Ct}=(\mathrm{Ct}$ target $-\mathrm{Ct}$ reference) sample $-(\mathrm{Ct}$ target $-\mathrm{Ct}$ reference $)$ calibrator $)$ [39]. The $C_{t}$ is the number of cycles needed for the fluorescence signal to reach a specific threshold level of detection and is negatively correlated with the amount of template nucleic acid in the reaction. All values are the normalized means \pm standard deviations (SD) of the results for two runs, each with two replicate samples.

\section{Sampling for intracellular metabolites}

Approximately $5 \times 10^{8} \mathrm{CFU}$ of bacteria were injected into a tube containing $15 \mathrm{~mL}$ pre-cooled solution of $75 \%$ methanol (v/v) with $70 \mathrm{mM}$ 4-(2-hydroxyethyl)-1piperazineethanesulfonic acid (HEPES) $\left(-80{ }^{\circ} \mathrm{C}\right)$. The contents of tube were quickly mixed by vortexing and then the tube was stored in the ice for $5 \mathrm{~min}$.

\section{Metabolite extraction}

Extraction of intracellular metabolites was performed using the cold ethanol method of Buchholz et al. [40] with some modifications. Briefly, the cells were centrifuged at $4,650 \mathrm{~g}$ for $10 \mathrm{~min}$ with a pre-cooled rotor of $4{ }^{\circ} \mathrm{C}$. The cell pellet was resuspended in $1 \mathrm{~mL}$ of cold $75 \%$ methanol $\left(-20^{\circ} \mathrm{C}\right)$. After rapid mixing, the mixture was frozen at $-80{ }^{\circ} \mathrm{C}$ for $5 \mathrm{~min}$ and thawed at $65{ }^{\circ} \mathrm{C}$ for $10 \mathrm{~min}$, which was performed with two consecutive repetitions. After the freeze-thaw cycle, proteins and cell fragments were removed by centrifugation at $12,000 \mathrm{~g}$ for $2 \mathrm{~min}$ at $4{ }^{\circ} \mathrm{C}$. The supernatant was stored at $-80{ }^{\circ} \mathrm{C}$ until further analysis.

\section{Chromatography}

Chromatographic separations were performed on an ACQUITY $^{\mathrm{TM}}$ UPLC System (Waters Corporation, Milford, MA). A BEH C18 reversed-phase column $(100 \times 2.1 \mathrm{~mm}$, $1.7 \mu \mathrm{m}$, Waters, MA, USA) and a BEH C18 guard column $(5 \times 2.1 \mathrm{~mm}, 1.7 \mu \mathrm{m})$ were used. The column was maintained at $37{ }^{\circ} \mathrm{C}$ with a flow rate of $0.4 \mathrm{~mL} / \mathrm{min}$. Mobile phase A was $0.1 \%$ formic acid (Sinopharm, Shanghai, PRC), while mobile phase B was acetonitrile (Sinopharm, Shanghai, PRC) modified by addition of $0.1 \%$ formic acid. Each sample was run twice: once in positive ionisation mode and once in negative ionisation mode. In positive mode, the gradient was $\mathrm{t}=0 \mathrm{~min}, 99 \% \mathrm{~B} ; \mathrm{t}=2 \mathrm{~min}, 70 \%$ $\mathrm{B}$; $\mathrm{t}=4 \mathrm{~min}, 25 \% \mathrm{~B} ; \mathrm{t}=7 \min , 25 \% \mathrm{~B} ; \mathrm{t}=9 \min , 0 \% \mathrm{~B} ; \mathrm{t}=$ $11.5 \mathrm{~min}, 0 \% \mathrm{~B} ; \mathrm{t}=12 \mathrm{~min}, 99 \% \mathrm{~B} ; \mathrm{t}=13.5 \mathrm{~min}, 99 \% \mathrm{~B}$. In negative mode, the gradient was $\mathrm{t}=0 \mathrm{~min}, 99 \% \mathrm{~B}$; $\mathrm{t}=2 \min , 70 \% \mathrm{~B} ; \mathrm{t}=4 \mathrm{~min}, 25 \% \mathrm{~B} ; \mathrm{t}=5 \mathrm{~min}, 25 \%$ $\mathrm{B} ; \mathrm{t}=7 \mathrm{~min}, 10 \% \mathrm{~B} ; \mathrm{t}=8 \mathrm{~min}, 0 \% \mathrm{~B} ; \mathrm{t}=10 \mathrm{~min}$, $0 \% \mathrm{~B} ; \mathrm{t}=10.4 \mathrm{~min}, 99 \% \mathrm{~B} ; \mathrm{t}=12.2 \mathrm{~min}, 99 \% \mathrm{~B}$.

\section{Mass spectrometry}

MS spectrometry was carried out on a Water Q-TOF Primer system (Waters Corporation, Milford, MA) with electrospray source ionization (ESI) operation in both positive and negative ion ionisation modes. Nitrogen was used as the drying gas. For both positive and negative ionisation modes, the capillary and conevoltage were set at $3 \mathrm{kV}$ and $55 \mathrm{~V}$, respectively. The desolvation gas was set to $650 \mathrm{~L} / \mathrm{h}$ at a temperature of $350{ }^{\circ} \mathrm{C}$, and the cone gas was set to $50 \mathrm{~L} / \mathrm{h}$ and the source temperature was set to $100{ }^{\circ} \mathrm{C}$. The data acquisition rate was set to $0.28 \mathrm{~s}$, with a $0.02 \mathrm{~s}$ interscan delay. Data was acquired with a scan range from 50 to $1000 \mathrm{Da}$.

\section{Data analysis}

The RT-qPCR data were analyzed using the ABI 7500 fast system. The quantity results based on RT-qPCR for 
tdh and trh genes at $25^{\circ} \mathrm{C}$ were used as datum for relative quantity data, which were respectively set as to 1 . The RT-qPCR value of $t d h$ or $t r h$ genes for other sample was converted to relative quantity data in comparison with the value from datum. A one-way ANOVA was performed by Microsoft office Excel 2007 (Microsoft, Redmond, USA) to determine significant differences at $\alpha=0.05$.

UPLC-MS spectra data were first processed by Markerlynx Applications Manager Version 4.1 (Waters, Manchester, UK), including the detection and retention time (R.T.) alignment of peaks in each chromatogram. Metabolites were identified by mass-to-charge ratios in the human metabolome database (HMDB). The processed data were then introduced to SIMCA-P 11.5 (Umetrics, Umea, Sweden). Multivariate statistical analysis method of principal component analysis (PCA) was performed to determine the trend of data which transforms the correlated variables dataset into a smaller number of independent variables, i.e., the principle components [41].

Pearson's correlation analysis was performed using the SPSS 17.0 (SPSS Inc., Chicago, USA). The correlation analysis was performed between the virulence genes expression and metabolome.

\section{Declarations}

Ethic approval and consent to participate

Not applicable.

\section{Consent for publication}

Not applicable.

\section{Availability of data and materials}

The data sets supporting the results of this article are included within the article and its additional file.

\section{Additional files}

Additional file 1: Table S1. Relative concentration of metabolites identified in Vibrio parahaemolyticus ATCC33846. (XLSX 123 kb).

Additional file 2: Table S2. Relative concentration of metabolites identified in Vibrio parahaemolyticus ATCC17802. (XLSX 113 kb).

Additional file 3: Table S3. Chemical taxonomy of significantly changed metabolitesof Vibrio parahaemolyticus ATCC33846. (DOCX 20 kb)

Additional file 4: Table S4. Chemical taxonomy of significantly changed metabolites of Vibrio parahaemolyticus ATCC17802. (DOCX $17 \mathrm{~kb}$ )

Additional file 5: Table S5. Primers sequences used in RT-qPCR. (DOCX $14 \mathrm{~kb}$ ).

\section{Abbreviations}

V. parahaemolyticus: vibrio parahaemolyticus; ATCC: American type culture collection; PCA: principal components analysis; UPLC \& Q-TOF MS: ultraperformance liquid chromatography \& quadrupole time-of-flight mass spectrometry; TDH: thermostable direct hemolysin; $t d h$ : thermostable direct hemolysin gene; TRH: TDH-related hemoysin; trh: TDH-related hemoysin gene; T3SS: type III secretion systems; T6SS: type VI secretion systems;
PC1: first principal component; PC2: second principal component; HMDB: human metabolome database; CoA: coenzyme A; TPP: triphenyl phosphate; LPE: Iysophosphatidylethanolamine; LPL: Iysophospholipid; DG: diacylglycerol; TSB: tryptic soy broth; TCBS: thiosulfate citrate bile sucrose agar; DEPC: diethyl pyrocarbonate; HEPES: 4-(2-hydroxyethyl)-1piperazineethanesulfonic acid.

\section{Competing interests}

The authors declare that they have no competing interests.

\section{Authors' contributions}

BF and YZ conceived the study. ZG and BF carried out experiments. YP provided the experimental equipment. $Y P$ and $Y Z$ supervised the analysis of data. BF and ZG wrote the draft. WZ and $Y Z$ revised the manuscript. All the authors read and approved the final manuscript.

\section{Acknowledgments}

We thank Instrumental Analysis Center of Shanghai Jiao Tong University for the use of UPLC/Q-TOF-MS. We thank Dr. Xiaohong Sun for providing the experimental equipment.

\section{Funding}

This work was supported by the National Natural Science Foundation of China [31271870, 31571917], the project of Science and Technology Commission of Shanghai Municipality [14DZ1205100, 14320502100], Key Project of Shanghai Agriculture Prosperity through Science and Technology [2014, 3-5 and 2015, 4-8], Shanghai Engineering Research Center of AquaticProduct Processing \& Preservation [11DZ2280300], and the "Dawn" Program of Shanghai Education Commission [15SG48].

\section{Author details}

${ }^{1}$ College of Food Science and Technology, Shanghai Ocean University, No. 999 Hu Cheng Huan Road, Shanghai, China. ${ }^{2}$ Shanghai Engineering Research Center of Aquatic-Product Processing \& Preservation, Shanghai, China. ${ }^{3}$ Laboratory of Quality \& Safety Risk Assessment for Aquatic Products on Storage and Preservation (Shanghai), Ministry of Agriculture, Shanghai, China.

Received: 9 August 2015 Accepted: 14 April 2016

Published online: 26 April 2016

\section{References}

1. Vibrio parahaemolyticus infections associated with consumption of raw shellfish-three states. 2006. CDC (Centers for Disease Control and Prevention). http://www.cdc.gov/mmwr/preview/mmwrhtml/mm5531a5. htm Accessed 21 Aug 2013.

2. Su YC, Liu C. Vibrio parahaemolyticus: a concern of seafood safety. Food Microbiol. 2007:24:549-58.

3. Sani NA, Ariyawansa KWS, Babji AS. Prevalence and risks of Vibrio parahaemolyticus in Black Tiger Shrimp (Penaeus monodon). Int J Infect Dis. 2008;12:e230-4.

4. Daniels NA, MacKinnon L, Bishop R, Altekruse S, Ray B, Hammond RM, et al. Vibrio parahaemolyticus infections in the United States, 1973-1998. J Infect Dis. 2000;181:1661-6.

5. U.S. Food and Drug Administration. Quantitative Risk Assessment on the Public Health Impact of Pathogenic Vibrio parahaemolyticus in Raw Oysters. Center for Food Safety and Applied Nutrition, Food and Drug Administration, U.S. Department of Health and Human Services;2005. http:// www.fda.gov/Food/FoodScienceResearch/RiskSafetyAssessment/ucm050421. htm. Accessed 23 Oct 2014.

6. Chao GX, Jiao XN, Zhou XH, Wang F, Yang ZQ, Huang JL, et al. Distribution of genes encoding four pathogenicity islands VPals., T6SS, Biofilm, and type I Pilus in food and clinical strains of Vibrio parahaemolyticus in China. Foodborne Pathog Dis. 2010;76:649-58.

7. Vibrio parahaemolyticus: How does infection with V. parahaemolyticus occur? CDC (Centers for Disease Control and Prevention). 2013. http://www.cdc. gov/vibrio/vibriop.html. Accessed 21 Oct 2013

8. Broberg CA, Calder TJ, Örth K. Vibrio parahaemolyticus cell biology and pathogenicity determinants. Microbes Infect. 2011;13:992-1001.

9. Zhang LL, Orth K. Virulence determinants for Vibrio parahaemolyticus infection. Curr Opin Microbiol. 2013;16:70-7. 
10. Letchumanan V, Chan K-G, Lee L-H. Vibrio parahaemolyticus: a review on the pathogenesis, prevalence, and advance molecular identification techniques. Front Microbiol. 2014;5:705.

11. Raghunath P. Roles of thermostable direct hemolysin (TDH) and TDH-related hemolysin (TRH) in Vibrio parahaemolyticus. Front Microbiol. 2015;5:805.

12. Miyamoto $Y$, Kato T, Obara Y, Akiyama S, Takizawa K, Yamai S. In vitro hemolytic characteristic of Vibrio parahaemolyticus: its close correlation with human pathogenicity. J Bacteriol. 1969;100(2):1147-9.

13. Honda T, Ni YX, Miwatani T. Purification and characterization of a hemolysin produced by a clinical isolate of Kanagawa phenomenon-negative Vibrio parahaemolyticus and related to the thermostable direct hemolysin. Infect Immun. 1988:56:961-5.

14. Raimondi F, Kao JP, Fiorentini C, Fabbri A, Donelli G, Gasparini N, Rubino A, Fasano A. Enterotoxicity and cytotoxicity of Vibrio parahaemolyticus thermostable direct hemolysin in in vitro systems. Infect Immun. 2000;68:3180-5.

15. Shinoda S. Sixty years from the discovery of Vibrio parahaemolyticus and some recollections. Biocontrol Sci. 2011;16:129-37.

16. Shirai $H$, Ito H, Hirayama T, Nakamoto $Y$, Nakabayashi $N$, Kumagai $K$, et al. Molecular epidemiologic evidence for association of thermostable direct hemolysin (TDH) and TDH-related hemolysin of Vibrio parahaemolyticus with gastroenteritis. Infect Immun. 1990;58:3568-73.

17. Honda T, lida T. The pathogenicity of Vibrio parahaemolyticus and the role of the thermostable direct hemoloysin and related hemolysin. Rev Med Microbiol. 1993;4:106-13.

18. Mahoney JC, Gerding MJ, Jones SH, Whistler CA. Comparison of the pathogenic potentials of environmental and clinical Vibrio parahaemolyticus strains indicates a role for temperature regulation in virulence. Appl Environ Microbiol. 2010;76:7459-65.

19. Liesenfeld DB, Habermann N, Owen RW, Scalbert A, Ulrich CM. Review of mass spectrometry-based metabolomics in cancer research. Cancer Epidemiol Biomarkers Prev. 2013;22:2182-201.

20. Siddiquee KAZ, Arauzo-Bravo MJ, Shimizu K. Metabolic flux analysis of pykF gene knockout Escherichia coli based on 13C-labeling experiments together with measurements of enzyme activities and intracellular metabolite concentrations. Appl Microbiol Biotechnol. 2004;63:407-17.

21. Chen X, Pan YJ, Sun XH, Zhao Y. Detection of th and tdh expression differences in Vibrio parahaemolyticus by real-time quantitative PCR. Microbiology China. 2011;38:1077-83 (in Chinese).

22. Zhao Q, Sun XH, Lu Y, Pan YJ, Zhao Y. Application of metabolic profiling for distinguishing different pathogenic Vibrio parahaemolyticus. Chem J Chinese U. 2012;33:1686-91 (in Chinese).

23. Vandesompele J, De Preter K, Pattyn F, Poppe B, Van Roy N, De Paepe A, et al. Accurate normalization of real-time quantitative RT-PCR data by geometric averaging of multiple internal control genes. Genome Biol. 2002;3:research 0034.1-0034.11

24. Tian Q, Stepaniants SB, Mao M, Weng L, Feetham MC, Doyle MJ, Yi EC, et al. Integrated genomic and proteomic analyses of gene expression in mammalian cells. Mol Cell Proteomics. 2004;3:960-69.

25. Nie L, Wu G, Zhang WW. Correlation between mRNA and protein abundance in Desulfovibrio vulgaris: a multiple regression to identify sources of variations. Biochem Biophys Res Commun. 2006;339:603-10.

26. Villas-Bôas SG, Højer-Pedersen J, Mats A, Jørn S, Jens N. Global metabolite analysis of yeast: evaluation of sample preparation methods. Yeast. 2005;22:1155-69.

27. Singh AK, Ulanov AV, Li Z, Jayaswal RK, Wilkinson BJ. Metabolomes of the psychrotolerant bacterium Listeria monocytogenes $10403 \mathrm{~S}$ grown at $37^{\circ} \mathrm{C}$ and $8{ }^{\circ} \mathrm{C}$. Int J Food Microbiol. 2011;148:107-14.

28. Ewald JC, Matta T, Zamboni N. The integrated response of primary metabolites to gene deletions and the environment. Mol Biosyst. 2013;9:440-6.

29. Quintaliani G, Buoncristiani U, Orecchini A, Pierini P, Ricci R, Reboldi GP. The Umbria Regional Registry for hemodialyzed and transplanted patients. Preliminary experience with an informatic procedure. Contrib Nephrol. 1994;109:96-9.

30. Goetzl EJ, An S. Diversity of cellular receptors and functions for the lysophospholipid growth factors lysophosphatidic acid and sphingosine 1-phosphate. FASEB J. 1998;12:1589-98.

31. Ghelardini C, Galeotti N, Lelli C, Bartolini A. M1 receptor activation is a requirement for arecoline analgesia. Farmaco. 2001;56:383-5.

32. Yang YR, Chang KC, Chen CL, Chiu TH. Arecoline excites rat locus coeruleus neurons by activating the M2-muscarinic receptor. Chin J Physiol. 2000;43:23-8.

33. Xie DP, Chen LB, Liu CY, Zhang CL, Liu KJ, Wang PS. Arecoline excites the colonic smooth muscle motility via M3 receptor in rabbits. Chin J Physiol. 2004;47:89-94
34. Yusuf $\mathrm{H}$, Yong SL. Oral submucous fibrosis in a 12-year-old Bangladeshi boy: a case report and review of literature. Int J Paediatr Dent. 2002:12:271-6.

35. Lin T, Wang JJ, Li JB, Liao C, Pan YJ, Zhao Y. Use of acidic electrolyzed water ice for preserving the quality of shrimp. J Microbiol Biotechnol Food Sci. 2013;61:8695-702

36. Coutard F, Lozach S, Pommepuy M, Hervio-Heath D. Real-time reverse transcription-PCR for transcriptional expression analysis of virulence and housekeeping genes in viable but nonculturable Vibrio parahaemolyticus after recovery of culturability. Appl Environ Microbiol. 2007;73:5183-9.

37. Li Q, Peng Z, Chen X, Sun X, Pan Y, Zhao Y. Selection of reference genes for virulence gene expression in Vibrio parahaemolyticus. Wei Sheng Wu Xue Bao. 2013;53:306-12 (in Chinese)

38. CA Kaysner, A DePaola, Jr. V. parahaemolyticus. In: Bacteriological Analytical Manual. U.S. Food and Drug Administration. 2004. http://www.fda.gov/food/ foodscienceresearch/laboratorymethods/ucm070830.htm. Accessed May 2004.

39. Livak KJ, Schmittgen TD. Analysis of relative gene expression data using real-time quantitative PCR and the $2^{-\Delta \Delta C t}$ method. Methods. 2001;25:402-8.

40. Buchholz A, Takors R, Wandrey C. Quantification of intracellular metabolites in Escherichia coli K12 using liquid chromatographic-electrospray ionization tandem mass spectrometric techniques. Anal Biochem. 2001;295:129-37.

41. Ogino A, Koshikawa H, Nakahara T, Uchiyama H. Succession of microbial communities during a biostimulation process as evaluated by DGGE and clone library analyses. J Appl Microbiol. 2001;91:625-35.

\section{Submit your next manuscript to BioMed Central and we will help you at every step:}

- We accept pre-submission inquiries

- Our selector tool helps you to find the most relevant journal

- We provide round the clock customer support

- Convenient online submission

- Thorough peer review

- Inclusion in PubMed and all major indexing services

- Maximum visibility for your research

Submit your manuscript at www.biomedcentral.com/submit

) Biomed Central 